\title{
Identification of Long Non-Coding RNAs Associated with Tomato Fruit Expansion and Ripening by Strand-Specific Paired-End RNA Sequencing
}

\author{
Jinyu Wang ${ }^{1,+}$, Yan Feng ${ }^{2,+}$, Xiaotao Ding ${ }^{2,+}\left(\mathbb{D}\right.$, Jingtian Huo ${ }^{1}$ and Wen-Feng Nie ${ }^{1, *}$ \\ 1 Department of Horticulture, College of Horticulture and Plant Protection, Yangzhou University, \\ Yangzhou 225009, China; wjy160123@163.com (J.W.); h181803206@163.com (J.H.) \\ 2 Shanghai Key Laboratory of Protected Horticultural Technology, Horticulture Research Institute, \\ Shanghai Academy of Agricultural Sciences, Shanghai 201403, China; fengyan@saas.sh.cn (Y.F.); \\ xiaotao198108@163.com (X.D.) \\ * Correspondence: wfnie@yzu.edu.cn \\ + These authors contributed equally.
}

check for updates

Citation: Wang, J.; Feng, Y.; Ding, X.; Huo, J.; Nie, W.-F. Identification of Long Non-Coding RNAs Associated with Tomato Fruit Expansion and Ripening by Strand-Specific Paired-End RNA Sequencing. Horticulturae 2021, 7 , 522. https://doi.org/10.3390/ horticulturae7120522

Academic Editors: Jinzhi Zhang, Pingxian Zhang and Changfei Guan

Received: 18 October 2021

Accepted: 22 November 2021

Published: 25 November 2021

Publisher's Note: MDPI stays neutral with regard to jurisdictional claims in published maps and institutional affiliations.

Copyright: (C) 2021 by the authors. Licensee MDPI, Basel, Switzerland. This article is an open access article distributed under the terms and conditions of the Creative Commons Attribution (CC BY) license (https:/ / creativecommons.org/licenses/by/ $4.0 /)$.

\begin{abstract}
As emerging essential regulators in plant development, long non-coding RNAs (lncRNAs) have been extensively investigated in multiple horticultural crops, as well as in different tissues of plants. Tomato fruits are an indispensable part of people's diet and are consumed as fruits and vegetables. Meanwhile, tomato is widely used as a model to study the ripening mechanism in fleshy fruit. Although increasing evidence shows that lncRNAs are involved in lots of biological processes in tomato plants, the comprehensive identification of lncRNAs in tomato fruit during its expansion and ripening and their functions are partially known. Here, we performed strand-specific paired-end RNA sequencing (ssRNA-seq) of tomato Heinz1706 fruits at five different developmental stages, as well as flowers and leaves. We identified 17,674 putative lncRNAs by referencing the recently released SL4.0 and annotation ITAG4.0 in tomato plants. Many lncRNAs show different expression patterns in fleshy fruit at different developmental stages compared with leaves or flowers. Our results indicate that lncRNAs play an important role in the regulation of tomato fruit expansion and ripening, providing informative lncRNA candidates for further studies in tomato fruits. In addition, we also summarize the recent advanced progress in lncRNAs mediated regulation on horticultural fruits. Hence, our study updates the understanding of lncRNAs in horticultural plants and provides resources for future studies relating to the expansion and ripening of tomato fruits.
\end{abstract}

Keywords: fruit ripening; fruit expansion; lncRNAs; horticultural crop; ssRNA-seq

\section{Introduction}

Non-coding RNAs (ncRNAs) belong to a subclass of eukaryotic transcripts that do not encode proteins [1-3]. The ncRNAs have emerged as the major products of the eukaryotic transcriptome with regulatory importance and function in various biological processes in both mammals and plants [4,5]. According to the regulatory roles, ncRNA can be divided into housekeeping ncRNAs and regulatory ncRNAs [6]. Housekeeping ncRNAs are abundantly and ubiquitously expressed in cells, which primarily regulate generic cellular processes. In contrast, regulatory ncRNAs are generally considered as crucial regulatory RNA molecules, regulating gene expression at epigenetic, transcriptional, and post-transcriptional levels [6]. Housekeeping ncRNAs include rRNAs, tRNAs, small nuclear RNAs (snRNAs), small nucleolar RNAs (snoRNAs), and telomerase RNAs. In addition, regulatory ncRNAs contain microRNA (miRNA), small interfering RNAs (siRNAs), piwi-interacting RNAs (piRNAs), promoter-associated transcripts (PATs), enhancer RNAs (eRNAs), circular RNAs (circRNAs), Y RNAs, and long noncoding RNAs (lncRNAs) [7-9]. LncRNAs longer than 200 nucleotides are a wide-spread subset of ncRNAs in the eukary- 
ote, emerging as essential regulators in plant growth and development [10-13], stress response [13-16], multiple metabolic pathways [17-20], and fruit ripening [21-23].

According to the genomic origins of lncRNAs, they are further divided into three categories in plants: (i) long intergenic ncRNAs (lincRNAs), (ii) intronic ncRNAs, and (iii) natural antisense transcripts (NATs) transcribed from complementary DNA strands of their associated genes [24]. At the beginning of studying lncRNAs, the differential display reverse transcription PCR (DDRT-PCR) was used to analyze the expression of the CsM10 gene in cucumber [25]. Later, a pollen-specific gene $Z m 401$, which also functions as a short open reading-frame mRNA (sORF mRNA) and/or noncoding RNA (ncRNA), was found to regulate other development [26]. With the development and advancement of sequencing technologies, IncRNAs have been widely identified and studied in both model and crop plants, such as Arabidopsis thaliana [27,28], Oryza sativa [29], Zea mays [30], Solanum lycopersicum [31], Triticum aestivum [32], Glycine max [33], Solanum tuberosum [34], Medicago truncatula [35], and Cucumis sativus [36]. For example, more than two thousand rice lncRNAs were identified through strand-specific RNA sequencing (ssRNA-seq) of rice anthers, pistils, seeds, and shoots, indicating their tissue-specific and stage-specific characteristics [37]. Similarly, wheat lncRNAs are also tissue-specific and are induced mainly by powdery mildew and heat stress [38]. In Arabidopsis, thousands of long lincRNAs are dynamically regulated after various stress treatments [27]. About 584 lncRNAs were identified and responded to simulated drought stress in Setaria italic [39]. In addition, IncRNAs are essential to reproductive growth in plants as well. For instance, a long-day-specific male-fertilityassociated lincRNA, LDMAR, is crucial to rice fertility under long-day conditions [40]. Moreover, in Arabidopsis, two different classes of lncRNAs transcribed from FLC, COLDAIR, and COOLAIR are involved in the epigenetic modification of the floral repressor gene FLC [41,42]. In early-flowering Arabidopsis ecotypes, the antisense long (ASL) transcript physically associates with the FLC locus and H3K27me3, indicating that ASL and COOLAIR play different roles in FLC silencing [43]. In rice and Arabidopsis, IncRNAs are involved in phosphate homeostasis $[44,45]$. These studies suggest that lncRNAs have multiple roles in plants, and lncRNAs could be diversely regulated to facilitate plant adaptation to changed environmental conditions and to deal with the internal response signals of plants as well.

The tomato (Solanum lycopersicum) fruit is a model used to understand the biology of fleshy fruit development and ripening [46]. The changes in color, flavor, aroma, texture, and nutrition of pulp during growth are emerging as important indexes of tomato fruit quality [47], and the molecular mechanism of fruit ripening is a group of closely coordinated and regulated physiological and biochemical processes [48]. Intensive studies of lncRNAs have shown their importance in the regulation of tomato fruit ripening and development. Tomato lncRNAs have been widely studied in recent years (Table 1). Generally, tomato lncRNAs have been identified and reported to be involved in tomato fruit ripening, coloration, pigment accumulation, ethylene pathway, chilling injury on fruits, Phytophthora infestans infection in tomato, acting as signaling in the interaction between plants and microbiomes, and association/interaction with DNA methylation (Table 1). Specifically, several lncRNAs were identified in tomato plants infected with tomato yellow leaf curl virus (TYLCV). For instance, the expression of slylnc0049 and slylnc0761 could inhibit the infection of TYLCV in tomatoes [49,50], and blocking expression of lncRNA 1459 could inhibit fruit ripening in tomatoes and induce the expression of numerous ripening-related genes [22]. Flowering is an essential stage of plant development, which influences fruit formation and production. A total of 10,919 lncRNAs, including 248 novel lncRNAs, were identified, of which 65 novel lncRNAs were significantly differentially expressed in the flowers, leaves, and roots [51]. These studies indicate that the emerging lncRNAs play essential regulatory roles in various developmental processes and stress responses in tomato plants and fruits. This concept could be further supported by the fact that lncRNAs have been widely studied in multiple horticultural crops, including strawberry, mango, walnut, kiwifruit, orange, pepper, gnetum luofuense, apple, sweet cherry, grapevine, pineapple, sea buckthorn, eucommia ulmoides, mulberry, and Cucumis melo (Table 2). 
Table 1. Summary of progress of lncRNAs on tomato plants and fruits.

\begin{tabular}{|c|c|c|}
\hline Num. & Biological Function/Main Finding & References \\
\hline 1 & $\begin{array}{l}\text { Identification of lncRNAs by strand-specific paired-end RNA sequencing of } \\
\text { tomato leaves, flowers, and roots }\end{array}$ & [51] \\
\hline 2 & $\begin{array}{l}\text { Integration and relationships between DNA methylation, lncRNAs, mRNAs, } \\
\text { and metabolites in ripening tomato fruit }\end{array}$ & [20] \\
\hline 3 & $\begin{array}{l}\text { The connection between lncRNAs and transposable elements, and between } \\
\text { lncRNAs and DNA CG methylation }\end{array}$ & {$[52,53]$} \\
\hline 4 & Regulating tomato fruit ripening & {$[20,22,31,54,55]$} \\
\hline 5 & $\begin{array}{l}\text { Function in trans-splicing event SlPsy1-ACoS-AS1, and generation of yellow } \\
\text { fruit in tomatoes }\end{array}$ & [56] \\
\hline 6 & LncRNA regulates tomato fruit cracking & [57] \\
\hline 7 & $\begin{array}{l}\text { LncRNA is involved in rhizobacterial strain-induced systemic resistance (ISR) } \\
\text { to the foliar pathogen Botrytis cinerea in leaves }\end{array}$ & [58] \\
\hline 8 & $\begin{array}{l}\text { LncRNAs regulate rhizosphere bacteria-induced tomato resistance to } \\
\text { Meloidogyne incognita in roots }\end{array}$ & [13] \\
\hline 9 & Function in regulating the resistance to Phytophthora infestans in tomato plants & {$[12,15,59-62]$} \\
\hline 10 & In response to tomato yellow leaf curl virus (TYLCV) interaction & {$[49,50]$} \\
\hline 11 & Regulation in tomato multicellular trichome formation & [63] \\
\hline 12 & In response to drought stress in tomato leaves & [64] \\
\hline 13 & In response to chilling injury in tomato fruits & [65] \\
\hline
\end{tabular}

Table 2. Summary of studies on lncRNAs in horticultural crops.

\begin{tabular}{cccc}
\hline Num. & Species & Biological Function & References \\
\hline 1 & Strawberry & Fruit ripening; anthocyanin accumulation & {$[23,66]$} \\
2 & Mango & Abiotic stress & {$[16]$} \\
3 & Walnut & Biotic stress & {$[21]$} \\
4 & Kiwifruit & Fruit ripening & {$[19]$} \\
5 & Orange & Fruit granulation & {$[68]$} \\
6 & Pepper & Fruit ripening & {$[11]$} \\
7 & Gnetum luofuense & Seed development & {$[69,70]$} \\
8 & Apple & Fruit anthocyanin accumulation & {$[71]$} \\
9 & Sweet cherry & Pollen development & {$[10]$} \\
10 & Grapevine & Different developmental stages of leaf, inflorescence, and berry tissues & {$[17]$} \\
11 & Pineapple & Crassulacean acid metabolism photosynthesis pathway in leaves & {$[72,73]$} \\
12 & Sea buckthorn & Fruit ripening & {$[74]$} \\
13 & Eucommia ulmoides & Rubber biosynthesis & {$[14]$} \\
15 & Mulberry & Abiotic stress & Biotic stress \\
16 & Banana & Fruit ripening & \\
\hline
\end{tabular}

Although numbers of lncRNAs have been identified in ripe tomato fruit and/or predicted mainly through the analysis of non-strand specific mRNA-seq data, the comprehensive characterization and identification of lncRNAs in tomato fruit during its expansion and ripening is not fully known, especially when building on SL4.0 and annotation ITAG4.0. Thus, to fully understand the lncRNA-mediated transcriptional regulation during tomato fruit expansion and ripening, the differentially expressed long non-coding genes were identified by strand-specific paired-end RNA sequencing (ssRNA-seq) and bioinformatics analysis in this study. In total, we identified 17,674 putative lncRNAs in our datasets during tomato fruit expansion and ripening. Compared with leaves and flowers, many lncRNAs showed differential expression patterns in the different developmental stages of fleshy tomato fruits. Our results indicate that lncRNAs play a prominent role in the regulation 
of tomato fruit expansion and ripening. Our findings provide informative resources for further studies to characterize the function of lncRNAs in tomato fruits.

\section{Materials and Methods}

\subsection{Plant Growth Conditions}

The seeds of tomato cultivar Heinz1706 were germinated at $25^{\circ} \mathrm{C}$. Plants were grown in the greenhouse, and the conditions in the greenhouse were set at $25^{\circ} \mathrm{C}$ during the day $(16 \mathrm{~h})$ and $22^{\circ} \mathrm{C}$ at night $(8 \mathrm{~h})$. Relative humidity in the greenhouse was set at about $70 \%$. To collect samples from different developmental stages of tomato fruit, the date of flowering was marked, and the flowers on the day of blooming were sampled as the flowers sample in this study. Fruits at $5 \mathrm{dpa}$ (days after pollination), $15 \mathrm{dpa}, 35 \mathrm{dpa}, 40 \mathrm{dpa}$, and $45 \mathrm{dpa}$ were harvested, respectively. The leaves were also sampled as the control group. Ten tissues from at least 5 independent plants were combined to form one biological replicate. All the sampled tissues were frozen immediately in liquid nitrogen and stored at $-80^{\circ} \mathrm{C}$ for further detection.

\subsection{RNA Isolation and Quality Control}

Total RNA was extracted from sampled tissues stored at $-80{ }^{\circ} \mathrm{C}$ via TRIzol (Thermo Fisher, Waltham, MA, USA). The RNA was first checked on $1 \%$ agarose gel. In addition, the RNA purity was checked using a NanoPhotometer ${ }^{\circledR}$ spectrophotometer (IMPLEN, Los Angeles, CA, USA). Finally, the RNA integrity was assessed using an RNA Nano 6000 Assay Kit of the Bioanalyzer 2100 system (Agilent Technologies, Santa Clara, CA, USA).

\subsection{Library Preparation and Sequencing}

RNA-seq libraries made from rRNA depleted RNA and poly(A)-depleted RNA was prepared according to a previously published paper [77]. A total amount of $1 \mu \mathrm{g}$ of RNA per sample was used as input material for the RNA library construction. In brief, rRNA was first removed from total RNA, and then the RNA was fragmented by sonication into 250-300 bp short fragments. The first strand of cDNA was synthesized with fragmented RNA as a template with random oligonucleotides as primers. Then, the RNA strand was degraded with RNase $\mathrm{H}$, and the second strand of cDNA was synthesized with dNTPs (dUTP, dATP, dGTP, and DCTP) as directed by DNA polymerase I. The purified doublestrand cDNAs were repaired, added with a tail and sequencing adaptor. The cDNA lengths between 350-400 bp were screened by AMPure XP beads. The second strand of cDNA was degraded, and PCR finally amplified the first strand of cDNAs to obtain the library, and was then sequenced on the Illumina HiSeq 2500 platform. The PE150 (paired-end $150 \mathrm{nt}$ ) sequencing was performed to obtain $12 \mathrm{G}$ raw data.

\subsection{Data Analysis}

Raw reads of FASTQ format were first processed through in-house perl scripts. Clean data (clean reads) were obtained after removing reads containing adapters, reads containing poly-N sequences, and reads of low quality from the raw data. Paired-end clean reads were aligned to the reference genome (Tomato genome version SL4.0) using HISAT2 v2.0.5 [78]. Novel transcript prediction: The mapped reads of each sample were assembled by StringTie (v1.3.3b) [79] by a reference-based approach. The tool of featureCounts v1.5.0-p3 was used to calculate the number of reads that were mapped to each gene [80]. The FPKM of each gene was then calculated based on the length of the gene and read count mapped to that gene [81].

\subsection{LncRNAs Calling}

Reference genome and gene model annotation files were downloaded from the genome website directly. All the transcripts were merged using Cuffmerge software (v2.2.1). The lncRNA expression was quantified using the Cuffquant and Cuffnorm modules. LncRNAs were then identified from the assembled transcripts following four steps: (1) removal of lowly expressed transcripts with FPKM $<0.5$; (2) removal of short transcripts 
$<200 \mathrm{bp}$ and $<2$ exons; (3) removal of the transcripts with protein-coding capability using CNCI, Pfam (Pfam scan, V3.2.0), and CPC2 database; (4) removal of the transcripts mapped within the $1 \mathrm{~kb}$ flanking regions of an annotated gene using Cuffcompare. Novel lncRNAs were named following the rules of HGNC (The HUGO Gene Nomenclature Committee). The characteristics of novel lncRNAs were compared with the known lncRNAs and mRNAs in the tomato genome.

\subsection{Differential Expression Analysis}

The transcripts and genes were quantified using StringTie software and reads per kilobase of transcript per million mapped reads (RPKM) was obtained. The edgeR was used for differential expression analysis. The resulting $p$-values were adjusted using Benjamini and Hochberg's approach for controlling the false discovery rate. Genes with I log2 (Fold Change) $\mid>1$ and padj $<0.05$ were assigned as differentially expressed.

\section{Results}

\subsection{Genome-Wide Identification of IncRNAs in Tomato Fruit at Different Developmental Stages}

The ssRNA-seq has become a powerful tool for discovering lncRNA, which facilitates the confirmation of the orientation of transcripts. We performed high-throughput strandspecific RNA-seq in the tomato line Heinz1706 at five developmental stages of tomato fruit: $5 \mathrm{dpa}$ (days after pollination), $15 \mathrm{dpa}, 35 \mathrm{dpa}, 40 \mathrm{dpa}$, and $45 \mathrm{dpa}$ to systematically identify lncRNAs related to tomato fruit expansion and ripening. Additionally, samples from flowers and mature leaves were also taken as the controls (Figure S1, Tables S1 and S2). We evaluated the coding potential of the remaining transcripts using a coding potential calculator (CPC) and coding-non-coding index (CNCI) and employed BLASTX against protein database PFAM to exclude those transcripts that might encode proteins. Finally, 17,674 transcripts were obtained in tomato fruits, flowers, and leaves, and defined as lncRNAs in tomatoes (Figure 1A and Table S3). It should be noted that there were 544 novel mRNA transcripts identified in this study according to the recently released tomato reference genome (SL4.0, Table S4).

A

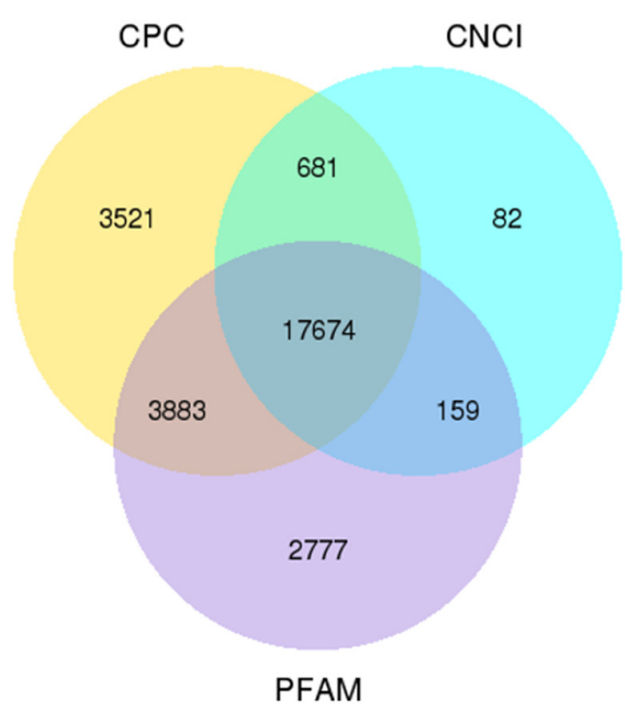

B

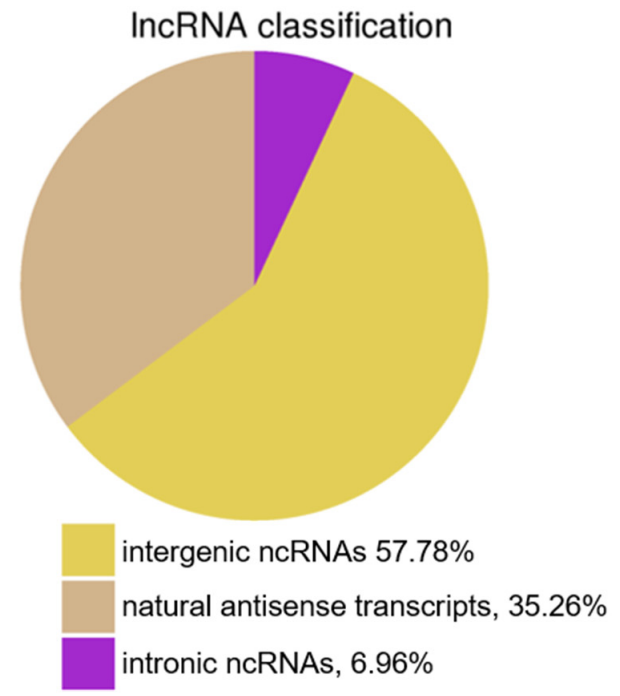

Figure 1. Characterization of all the lncRNAs identified in this study. (A) Venn diagram of lncRNA candidates. The coding transcripts were excluded by using the CPC (coding potential calculator), CNCI (coding-non-coding index), and Pfam database. The 17,674 was the number of lncRNAs that were commonly predicted by CPC, CNCI, and Pfam database. (B) Classification of the identified lncRNAs. Among 17,674 lncRNAs, 57.78\%, 35.62\%, and $6.96 \%$ are intergenic, natural antisense transcriptional, and intronic lncRNAs, respectively. 


\subsection{Genome-Wide lncRNAs Expression Pattern and Their Distribution on Tomato Chromosomes}

We found that there were 10,212 (57.78\%) long intergenic ncRNAs (lincRNAs), 1230 (6.96\%) intronic ncRNAs, and $6232(35.26 \%)$ natural antisense transcripts (Figure 1B). Generally, we found 12,896, 9961, 12,007, 10,256, 10,014, 9431, and 8036 lncRNAs in flowers, 5 dap fruits, 15 dpa fruits, 35 dpa fruits, 40 dpa fruits, 45 dpa fruits, and leaves, respectively; among which there were $1492,888,979,861,801,986$, and 608 considered as expressed lncRNAs $($ FPKM > 1) [82] (Figure 2A).

\begin{tabular}{lll}
\hline Sample & $\begin{array}{l}\text { Number of } \\
\text { identified IncRNAs }\end{array}$ & $\begin{array}{l}\text { Number of expressed } \\
\text { IncRNAs (FPKM > 1) }\end{array}$ \\
\hline Flowers & 12,896 & 1492 \\
5dpa fruits & 9961 & 888 \\
15dpa fruits & 12,007 & 979 \\
35dpa fruits & 10,256 & 861 \\
40dpa fruits & 10,014 & 801 \\
45dpa fruits & 9431 & 986 \\
Leaves & 8036 & 608 \\
\hline
\end{tabular}

B

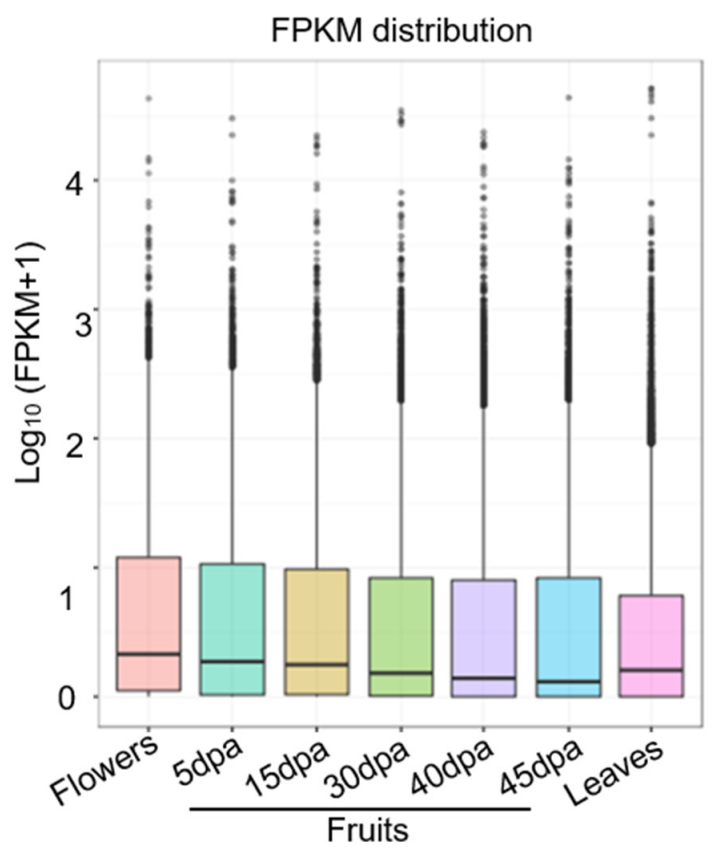

c
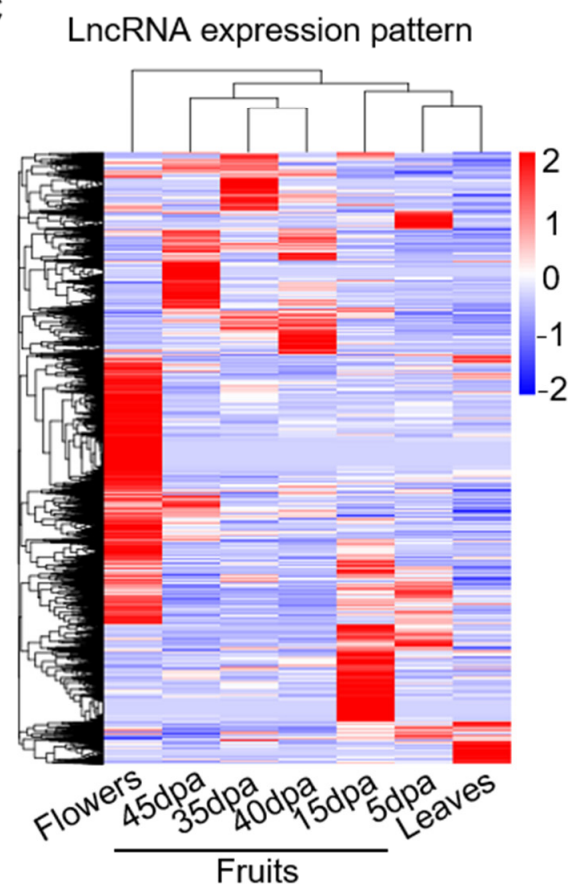

Figure 2. Tissue specific expression pattern and expression level of lncRNAs in tomato fruits at different stages. (A) The number of lncRNAs identified in different tissues and in different stages of tomato fruits. (B) The boxplot representation showing the expression level of transcripts in the indicated samples. (C)The heatmap representation of all of the identified lncRNAs in this study. The expression patterns were varied among flowers, fruits, and leaves.

Our identified lncRNAs were distributed over all the chromosomes as shown in the detailed physical position in Table S3. All the transcripts in fruits displayed a decreased trend with the increasing days after pollination (Figure 2B), consistent with our previous 
study [82]. As shown in Figure 2C, we found that the expression patterns differed among flowers, fruits, and leaves.

\subsection{Characterization of $\ln R N A$ Identified in the Tomato Genome}

We first analyzed the structure of the lncRNAs identified in this study. As shown in Figure 3A, the exon numbers of most known lncRNAs (annotated lncRNAs) are primarily enriched in the region from 0 to 5 , while the number of exons for the mRNA ranged from 0 to 20 . Unlike mRNA, we found that tomato annotated lncRNAs were mainly located at the length region size of 200 to $2000 \mathrm{nt}$ (Figure 3B). Figure 3C showed that the ORF lengths of lncRNAs were mainly enriched in the region from 0 to $300 \mathrm{nt}$. Compared to the known annotated lncRNAs in the tomato genome, the lengths of identified novel lncRNAs in our study were much shorter, and the number of exons were fewer (Figure 3A,B). However, the lengths of ORFs between the annotated and novel lncRNAs were similar (Figure 3C). These results were consistent with previous studies in plants and animals that lncRNAs are shorter and have fewer exons than protein-coding genes [83,84].

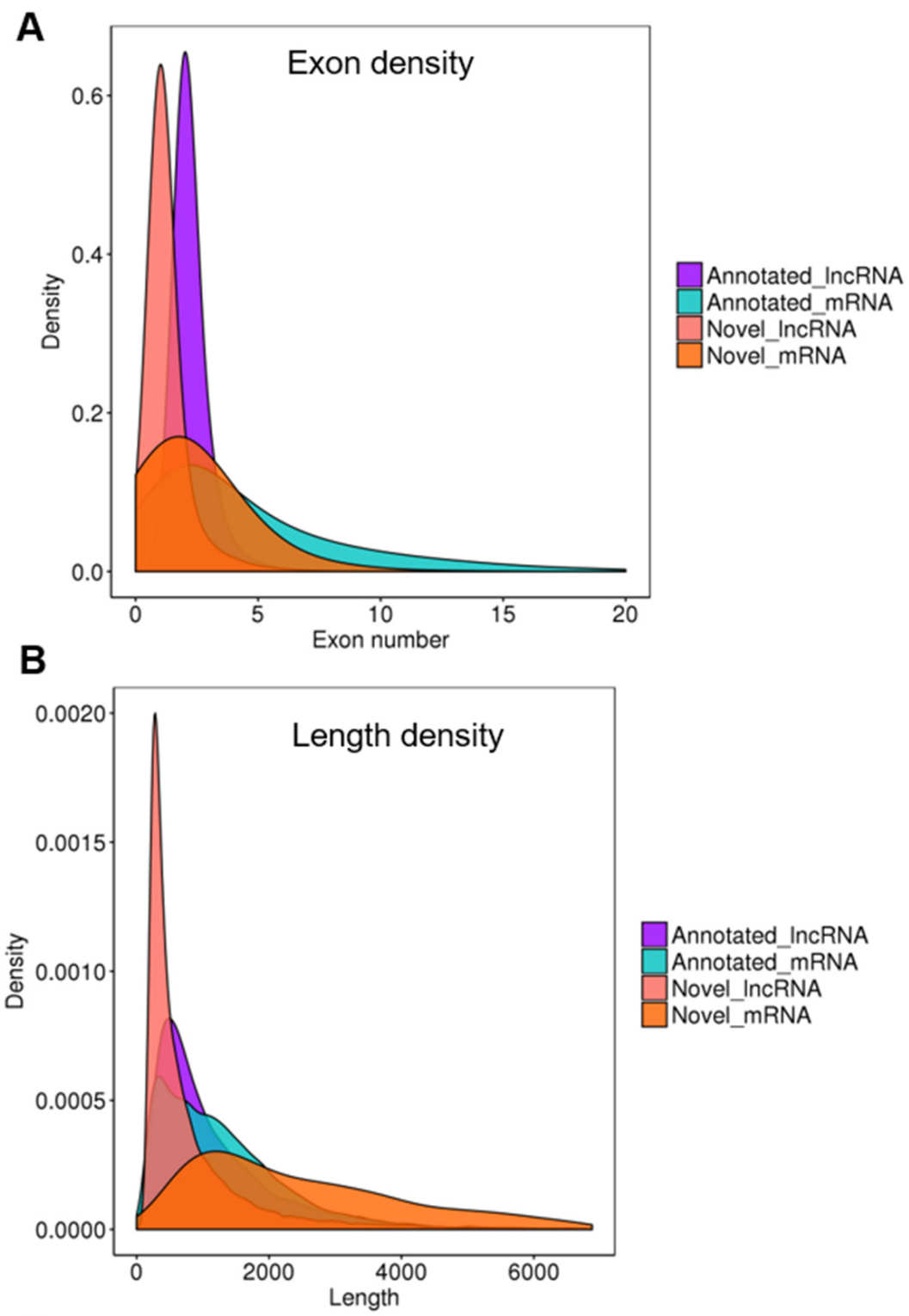

Figure 3. Cont. 


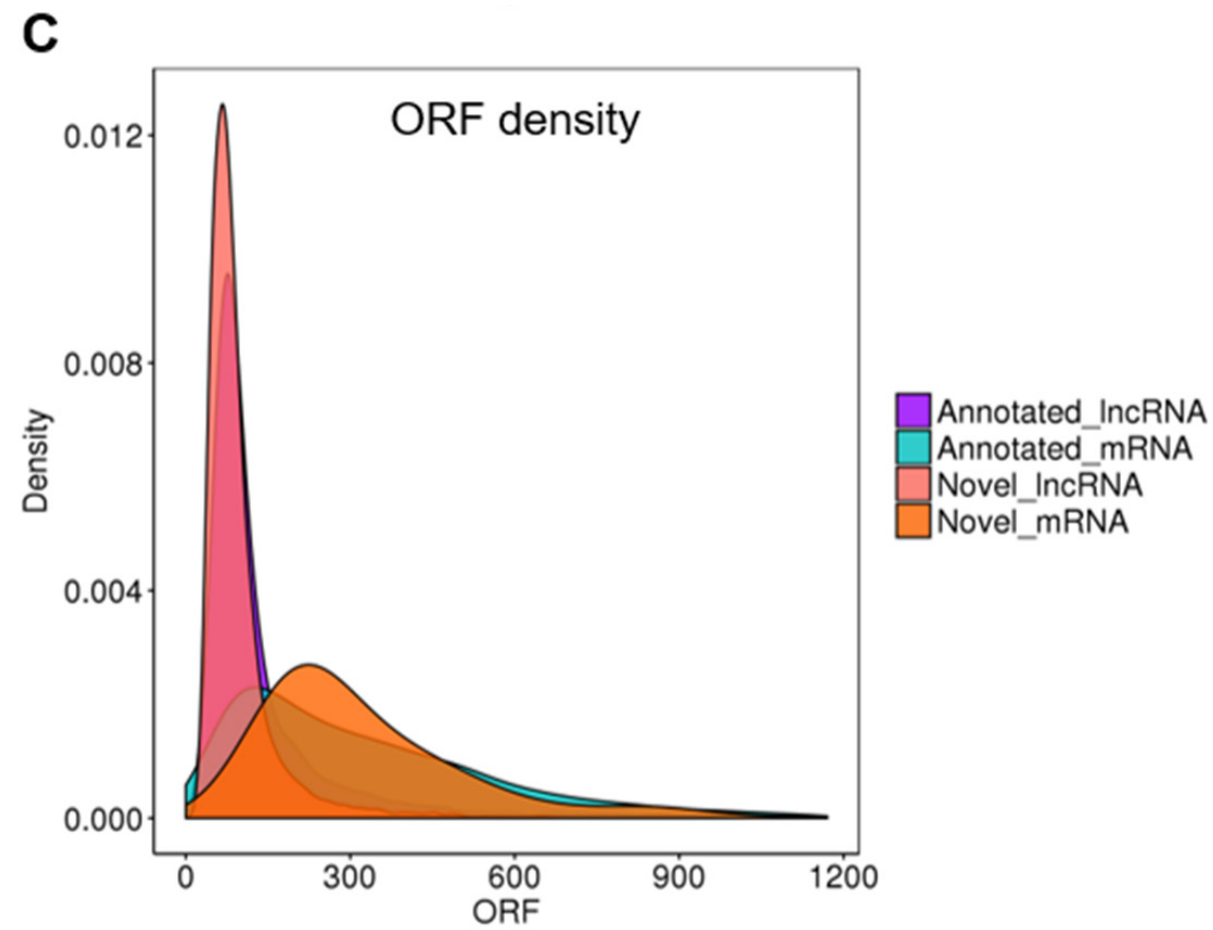

Figure 3. Analysis of lengths, exons, and ORFs of tomato lncRNAs identified in this study when by referencing SL4.0 and annotation ITAG4.0 in tomato. The density representation of number of exons (A), length (B), and length of ORFs (C) of identified lncRNAs. ORF, open reading frame. Annotated_lncRNA indicates the lncRNA already identified based on the public datasets. Novel_lncRNA indicates the lncRNA newly identified in this study.

\subsection{Analysis of Tomato Tissue- and Stage-Dependent lncRNAs during Fruit Expansion and Ripening}

The ssRNA-seq datasets were further used to explore the tissue- and stage-dependent lncRNAs expressed in Heinz1706 tomato fruits at five developmental stages, as well as flowers and mature leaves. Overall, our analysis showed a massive transcriptional reprogramming in response to fruit expansion and ripening (Figure 2B and Figure S2), as well as lncRNAs (Figure 2C). Compared to flowers, there were 1223, 2688, 1960, 2224, and 2251 up-regulated lncRNAs, and 3770, 3362, 3580, 3943, and 4295 down-regulated lncRNAs expressed at the $5 \mathrm{dpa}, 15 \mathrm{dpa}, 35 \mathrm{dpa}, 40 \mathrm{dpa}$, and $45 \mathrm{dpa}$, respectively (Figure 4A). Finally, 126 up-regulated and 1530 down-regulated lncRNAs were shared by comparing 5 dpa vs. flowers, 15 dpa vs. flowers, 35 dpa vs. flowers, 40 dpa vs. flowers, and 45 dpa vs. flowers (Figure 4B,C). The heatmap presentations show that the transcript levels of commonly up-regulated lncRNAs were increased in fruits compared to flowers but not in leaves (Figure 4D). Transcript levels of commonly down-regulated lncRNAs were decreased in fruits compared to flowers, as well as in leaves (Figure 4E). 
A

\begin{tabular}{lll}
\hline Sample & $\begin{array}{l}\text { Up- } \\
\text { regulated }\end{array}$ & $\begin{array}{l}\text { Down- } \\
\text { regulated }\end{array}$ \\
\hline 5dpa fruits vs. flowers & 1223 & 3770 \\
15dpa fruits vs. flowers & 2688 & 3362 \\
35dpa fruits vs. flowers & 1960 & 3580 \\
40dpa fruits vs. flowers & 2224 & 3943 \\
45dpa fruits vs. flowers & 2251 & 4295 \\
\hline
\end{tabular}

B

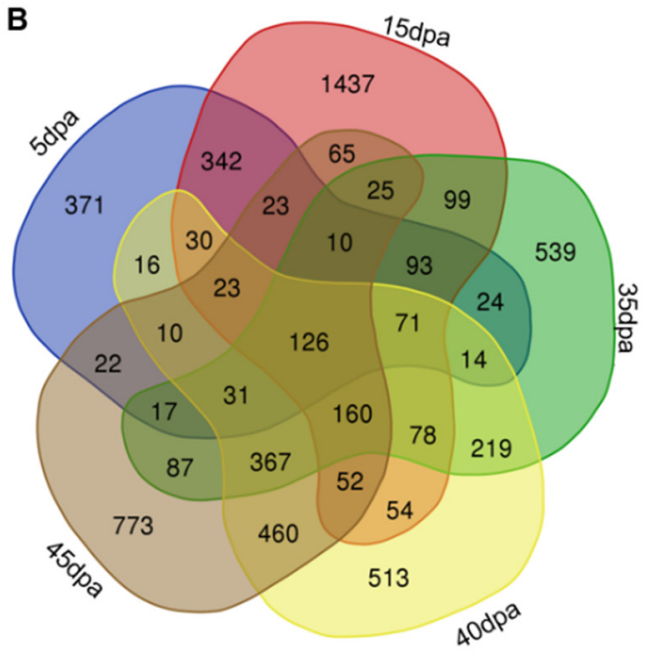

C

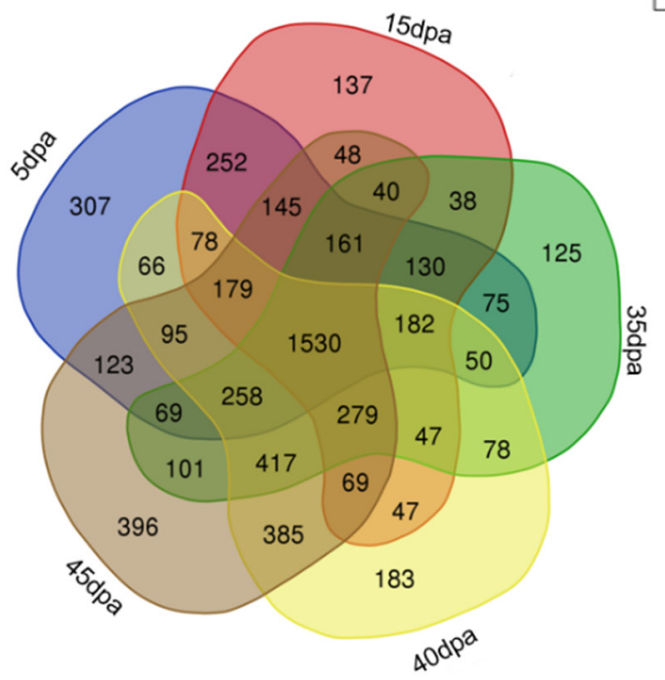

D

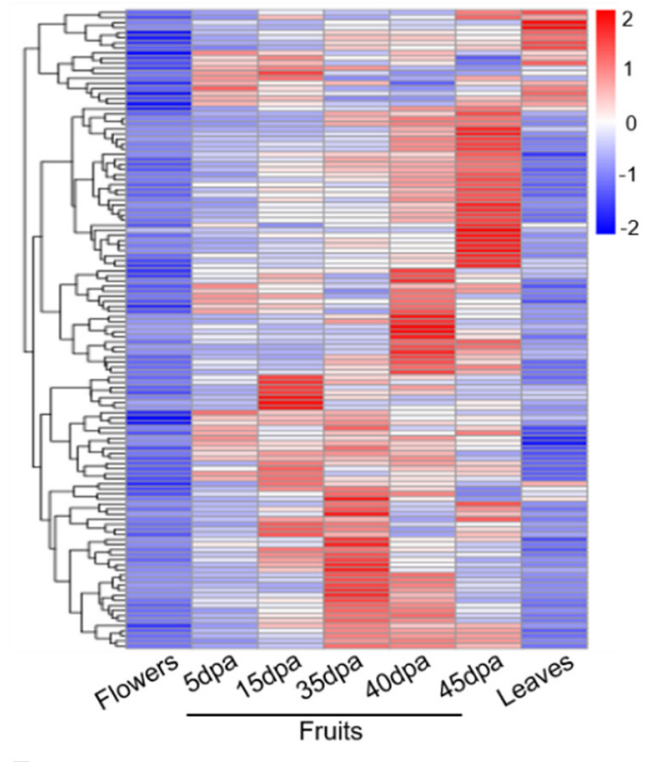

E

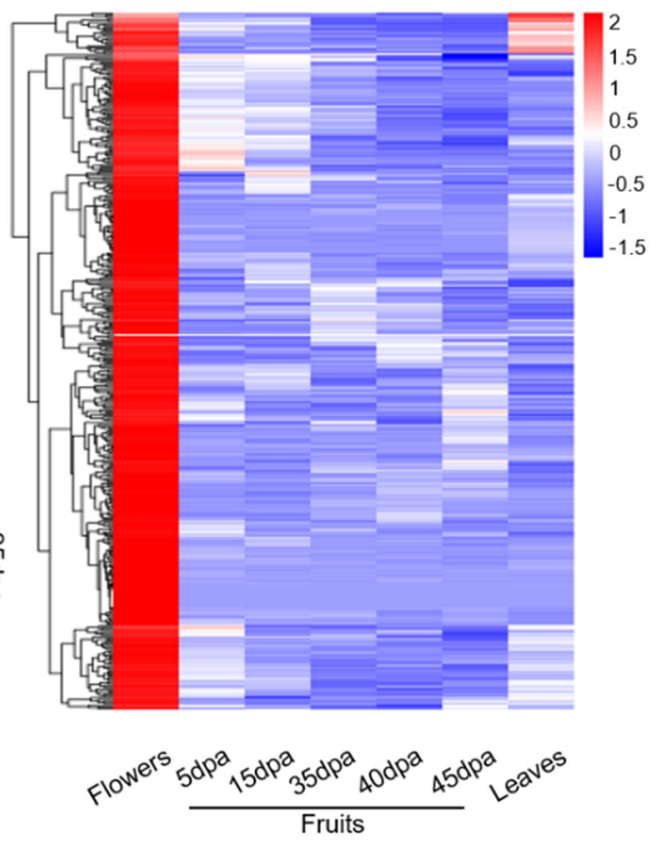

Figure 4. Characterization of differentially expressed lncRNAs between indicated comparisons. (A) The number of upregulated and down-regulated lncRNAs in indicated fruit samples compared to flowers. Flowers were sampled at the day of flowering. (B,C) Venn diagram shows the commonly up-regulated (B) and down-regulated (C) lncRNA in tomato fruits at different developmental stages compared to flowers. (D) Heatmap representation of the 126 lncRNA levels of commonly up-regulated in (C). (E) Heatmap representation of the lncRNA levels of commonly down-regulated in (D). The lncRNAs with PFKM value more than 1 in flowers were collected to do the heatmap representation in (E).

\subsection{Specific lncRNA Candidates in Regulating Tomato Fruit Expansion and Ripening}

To isolate the lncRNA candidates that may be essential in regulating the fruit expansion and ripening, we found 18 lncRNAs (names of lncRNAs marked with purple) whose expression levels were consistently increased (Figure 5A) and 14 lncRNAs (names of lncRNAs marked with blue) were consistently decreased (Figure 5B) during the whole developmental cycle of fruits. The fruits at 35 dpa were fully expanded and were then 
starting the ripening process [82]. We also displayed the cluster of lncRNAs that increased during fruit expansion stages but decreased in the following ripening stages. We observed that 33 lncRNAs were abundantly expressed at 35 dpa compared to other stages (Figure 5C). The expression patterns of those lncRNAs, whose detailed information is shown in Tables S3 and S5, were different in tomato fruits, unlike that in flowers and leaves, suggesting that multiple lncRNAs are essential for fruit development and ripening, and that expression patterns of lncRNAs are tissue-dependent in tomato.

A

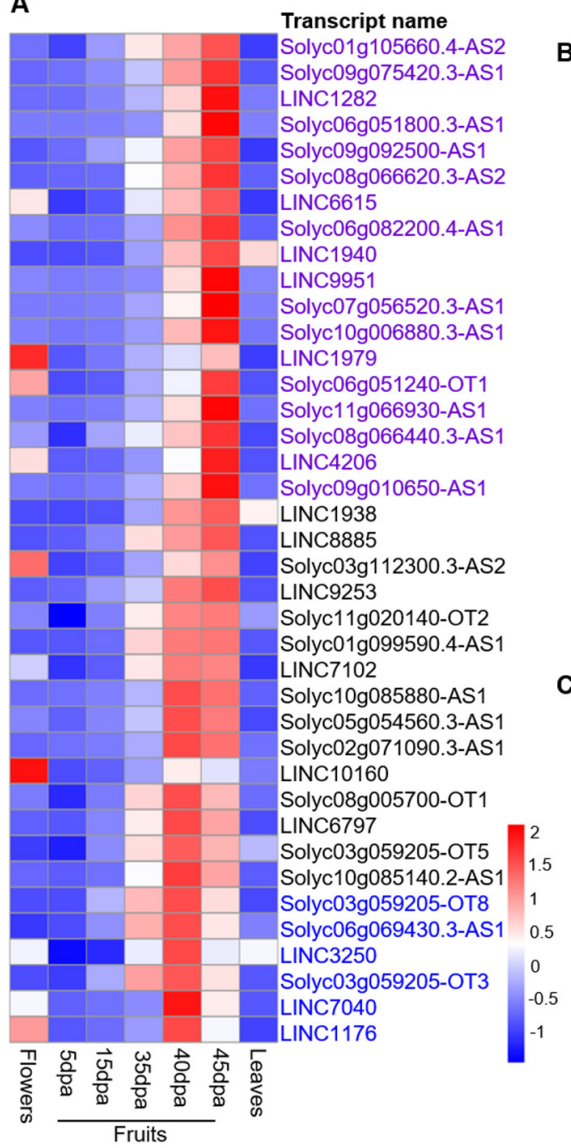

B
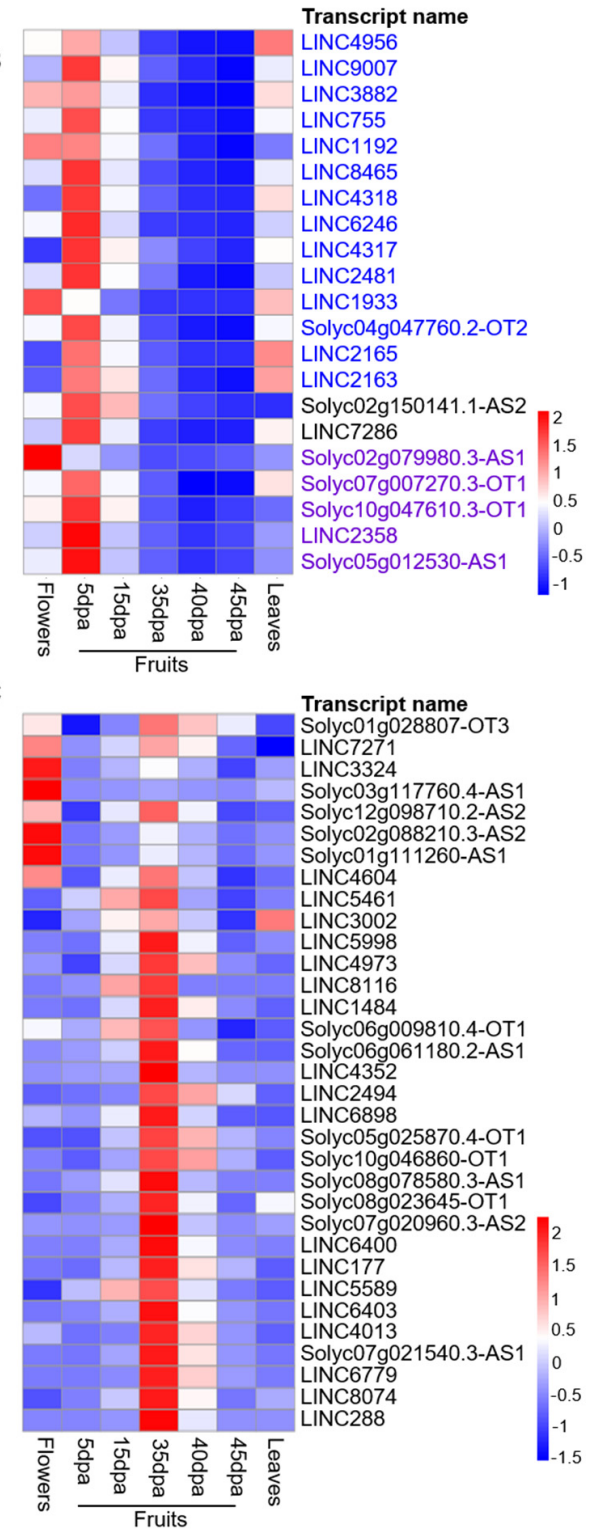

Figure 5. Expression levels of lncRNAs showing specific patterns during the expansion and ripening of fruits. (A,B) Heatmap representation of expression levels of lncRNAs consistently increased (A), and consistently decreased (B) in fruits from $5 \mathrm{dpa}$ to $40 \mathrm{dpa}$. The names of lncRNAs marked with purple indicates whose expression were increased in $45 \mathrm{dpa}$ fruits compared to $40 \mathrm{dpa}$ fruits. The names marked with black indicates no changes, and with blue indicated the expression levels were decreased in 45 dpa fruits compared to 40 dpa fruits. (C) Heatmap representation of the subset lncRNAs whose expression levels were consistently increased to reach the peak at $35 \mathrm{dpa}$ and then consistently decreased in fruits from 35dpa to $45 \mathrm{dpa}$. All the lncRNAs are selected based on the foldchange more than 2 in the comparison between the two adjact developmental stages. The levels of lncRNAs in flowers and leaves were displayed as the control. 


\subsection{Biological Function Analysis of $\operatorname{lncRNAs}$ in Regulating Tomato Fruit Expansion and Ripening}

To understand the function of specific lncRNAs that were isolated with tomato fruit expansion and ripening, Kyoto Encyclopedia of Genes and Genomes (KEGG) analyses were performed in genes co-localized and co-expressed with the lncRNAs shown in Figure 5. By KEGG analysis, we found that multiple pathways were enriched in the co-expressed genes (Figure 6A,C,E) and co-localized genes (Figure 6B,D,F) of the lncRNAs that were varied at different tomato fruit developmental stages. Among these, pathways enriched in genes co-expressed with those lncRNAs with consistently increased levels in fruits at the stages from $5 \mathrm{dpa}$ to $40 \mathrm{dpa}$, pathways corresponding to "endocytosis" and "regulation of autophagy" were significantly enriched (Figure 6A), while pathways of "photosynthesisantenna proteins" and "glutathione metabolism" were enriched in the co-localized genes with the same lncRNAs (Figure 6B). Pathways related to "ribosome", "DNA replication", "homologous recombination", and "plant-pathogen interaction" were significantly enriched in genes co-expressed with those lncRNAs with consistently decreased levels in fruits at the stages from 5 dpa to 40 dpa (Figure 6C), while no pathway was significantly enriched in the genes co-localized with the same lncRNAs (Figure 6D). In addition, we found that "plantpathogen interaction", "phenylalanine metabolism", and "phenylpropanoid biosynthesis" were significantly enriched with the genes co-expressed with the subset of lncRNAs whose expression levels were consistently increased at the fruit expansion stages but consistently decreased at the ripening stages (Figure 6E), but no pathways were significantly enriched in the genes co-localized with the same lncRNAs (Figure 6F).

A

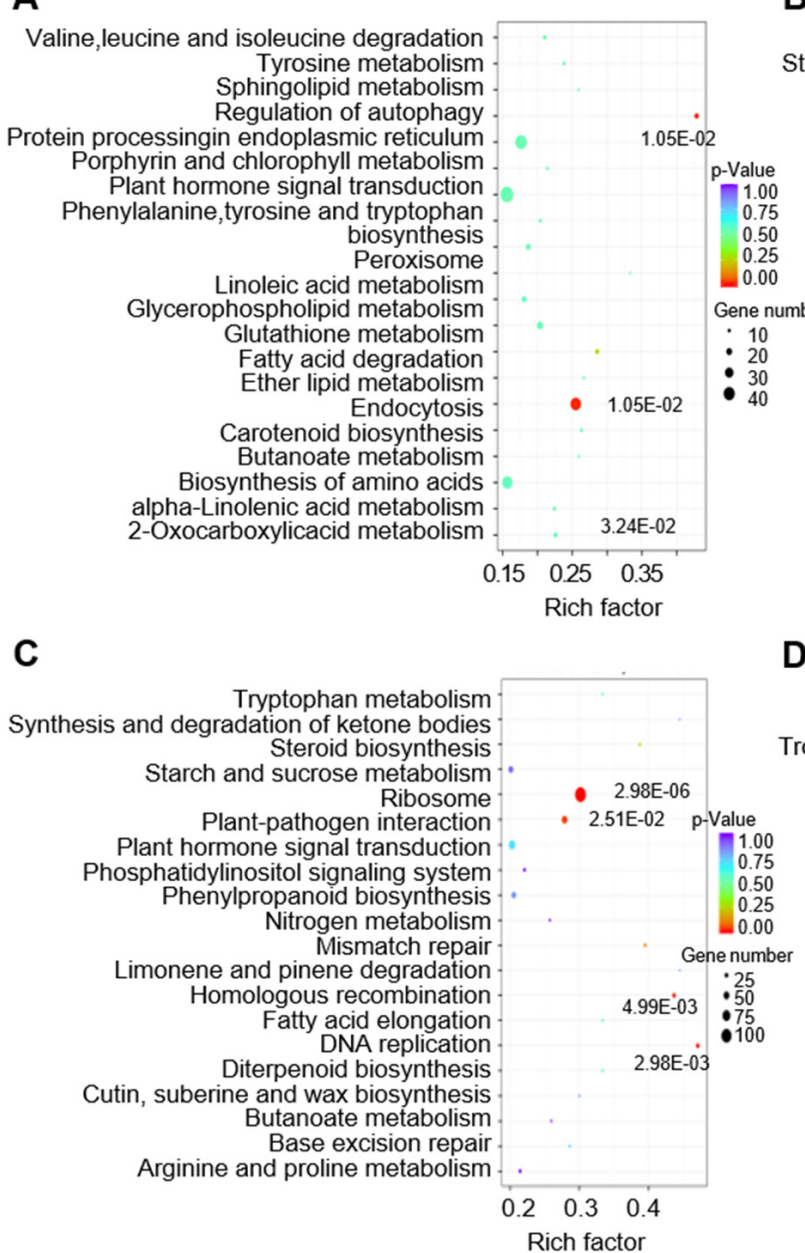

B

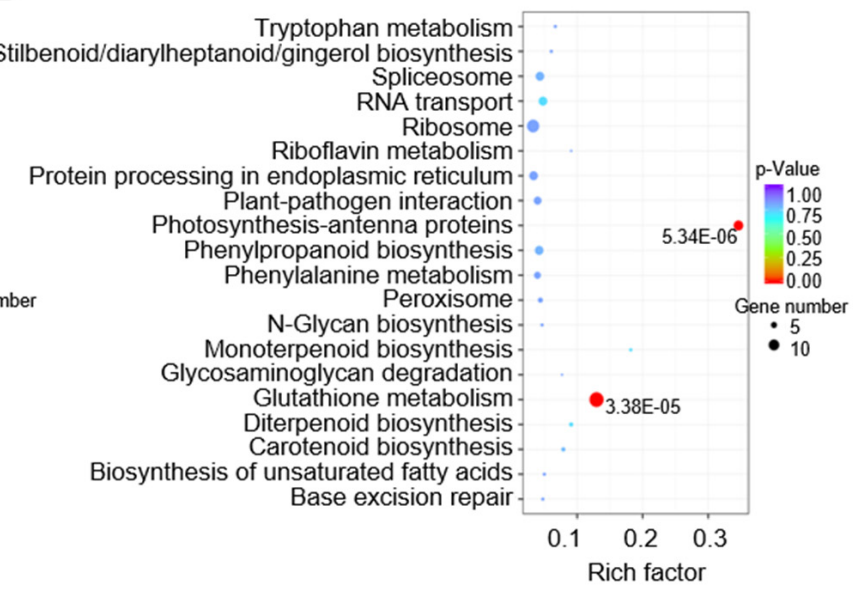

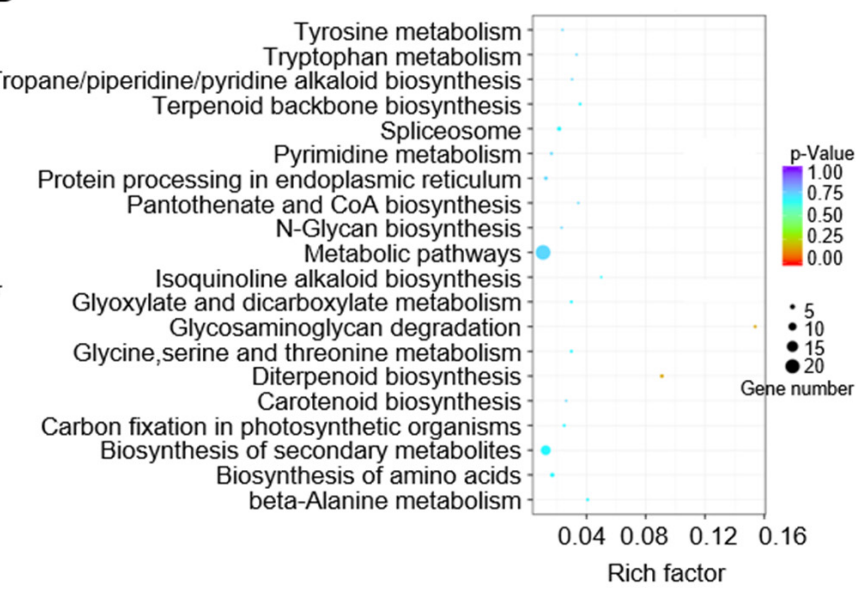

Figure 6. Cont. 
E

Valine,leucine and isoleucine degradation Stilbenoid/diary/heptanoid/gingerol biosynthesis

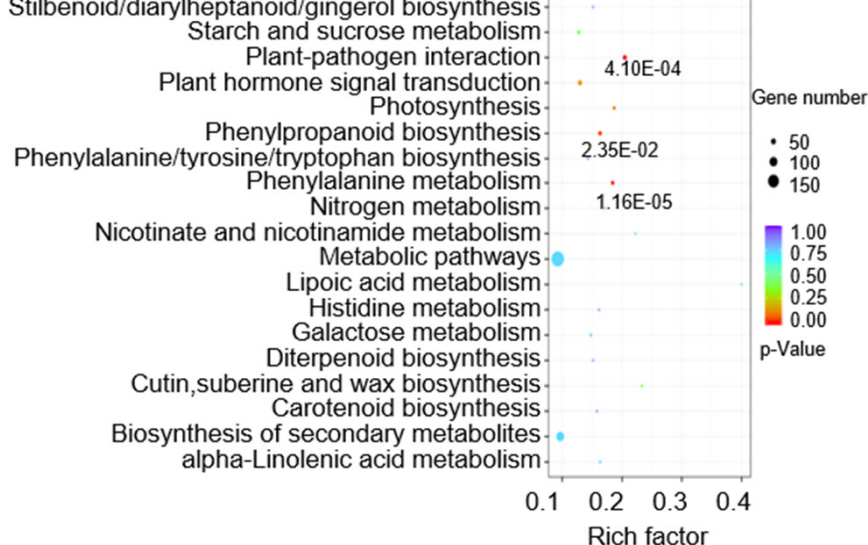

$\mathbf{F}$

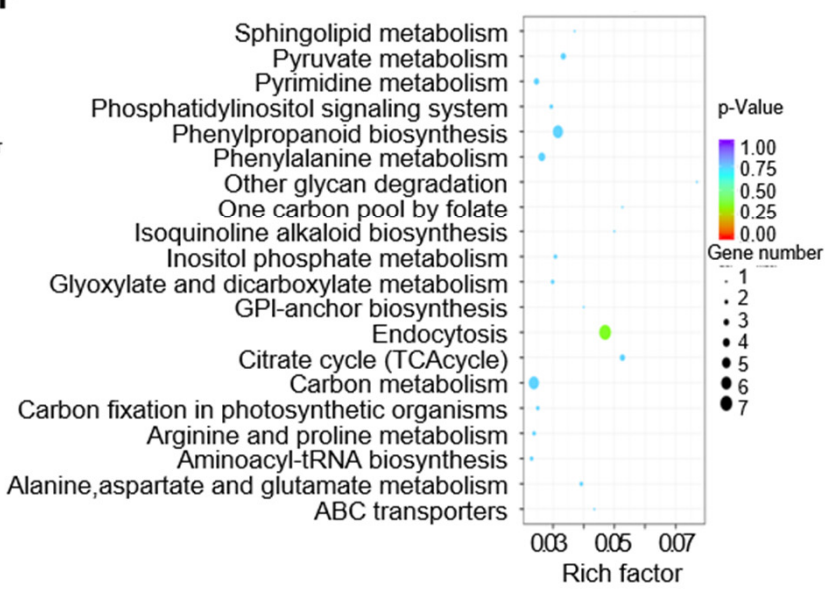

Figure 6. Biological function analysis of genes co-expressed and co-localized with classified lncRNAs. (A,B) KEGG analysis of genes co-expressed (A) and co-localized (B) with lncRNAs whose expression levels consistently increased in fruits from 5dpa to 40dpa, related to Figure 5A. (C,D) KEGG analysis of genes co-expressed (C) and co-localized (D) with lncRNAs whose expression levels consistently decreased in fruits from $5 \mathrm{dpa}$ to $40 \mathrm{dpa}$, related to Figure 5B. (E,F) KEGG analysis of genes co-expressed (E) and co-localized (F) with lncRNAs isolated in Figure 5C. GPl, glycosylphosphatidylinositol. The $p$-value of significantly enriched pathway was marked accordingly.

\section{Discussion}

It has been known that lncRNAs play essential roles in diverse biological processes in plants. In tomatoes, thousands of lncRNAs have been identified in flower and fruit tissues based on RNA-seq datasets [51]. However, the identification of lncRNAs in fruit ripening is still partial. This study identified a surprisingly large number $(17,674)$ of lncRNAs by ssRNA sequencing in tomato fruits, flowers, and leaves. A set of lncRNAs exhibit temporal expression specificity (Figure 5), implying that specific roles for lncRNAs are essential at multiple stages of tomato fruit development, such as manipulating fruit expansion and ripening.

Horticultural fruits are an important energy source providing humans with essential nutrients. Recent studies have extensively discovered a large number of lncRNAs from various horticultural crops (Table 2). LncRNAs are involved in the layer regulation of gene expression, as well as in epigenetic modification. Epigenetic modifications could enhance the phenotypic plasticity of plants and diversity of foods and the stability of crops in response to the increasing requirements for the daily nutritious diet [47]. Hence, the lncRNAs identified in tomato plants building on the recently released SL4.0 genome in our study could be further used to uncover the epigenetic mechanisms in regulating the quality and yield of tomato fruits. Tomato fruit ripening is a genetically programmed process that includes the initiation, maintenance, and reorganization of multiple pathways at the transcriptional level to further drive ethylene signals and ripening-related events. These various responses during fruit ripening are directly regulated by gene expression, which is plausibly affected by lncRNAs. LncRNAs containing binding sites of miRNAs could act as a noncanonical target mimic to modulate gene expression. In this study, several lncRNAs were isolated in the stages of tomato fruit expansion and ripening, providing valuable candidates to uncover the multiple roles of lncRNAs in fruit development. It should be noted that those candidate lncRNAs potentially regulating tomato fruit ripening and expansion need to be further tested in the future. With the wide application of gene editing by CRISPR, it's possible to investigate the detailed genetic function of these candidate lncRNAs in the signaling pathway in response to fruit quality regulation and metabolism of the carbohydrates in further study. Our ssRNA-seq results show that the lncRNAs pattern in flowers, fruits, and leaves are different, suggesting that the lncRNAs in tomatoes are tissue-dependent, consistent with the observation in the rice [37]. Interestingly, the number of identified lncRNAs in flowers is higher than that of fruits and leaves in our 
ssRNA-seq results, implying that lncRNAs are more active in flower tissue. Considering that in rice and Arabidopsis lncRNAs have been reported to influence fertility [40] and FLCmediating flowering through histone methylation modification [43], it is meaningful to test the biological functions of those tomato lncRNAs that are uniquely expressed in flowers in the future, thus to enhance the layers of reproductive mechanisms in horticultural plants.

The KEGG analysis is performed in co-expressed and co-localized genes with those lncRNAs displayed specific expression patterns during the expansion and ripening of tomato fruits, which suggest that endocytosis and autophagy may be the potential targeted process by lncRNAs in tomato fruits. Moreover, our KEGG analysis result indicates that fruit expansion- and ripening-dependent lncRNAs function in the interaction between plant and pathogen. Our results suggest that the lncRNAs also regulate the metabolism of glutathione during the ripening, similar to the previous result that cell redox and reactive oxygen species (ROS) are regulated by histone variant H2A.Z in tomato fruit [82]. The roles of epigenetic modification mediated cell redox in fruit ripening need to be tested in further studies. In conclusion, we have characterized and identified several specific lncRNAs in the regulation of tomato fruit expansion and ripening. We consider that lncRNAs screened in this study may provide a valuable resource for manipulating the gene regulatory network responding to fruit expansion and ripening in the tomato.

Supplementary Materials: The following are available online at https: / www.mdpi.com/article / 10.3390/horticulturae7120522/s1, Figure S1: Percent of reads mapped to different genomic regions in flowers, fruits, and leaves of tomato; Figure S2: The abundance of all of the expressed mRNA in indicated samples; Table S1: Sequencing reports; Table S2: Mapping reports; Table S3: All the lncRNAs identified in this study; Table S4: Novel mRNA identified in this study; Table S5: LncRNA transcripts FPKM.

Author Contributions: W.-F.N. conceived and designed the research; J.W., Y.F., X.D. and J.H. performed the research; W.-F.N. analyzed, interpreted the data, and wrote the manuscript. All authors have read and agreed to the published version of the manuscript.

Funding: This research was funded by Natural Science Foundation of Jiangsu Province grant number [BK20200948].

Institutional Review Board Statement: Not applicable.

Informed Consent Statement: Not applicable.

Conflicts of Interest: The authors declare that they have no conflict of interest.

\section{References}

1. Cech, T.R.; Steitz, J.A. The Noncoding RNA Revolution-Trashing Old Rules to Forge New Ones. Cell 2014, 157, 77-94. [CrossRef] [PubMed]

2. Rymarquis, L.A.; Kastenmayer, J.P.; Hüttenhofer, A.G.; Green, P.J. Diamonds in the rough: mRNA-like non-coding RNAs. Trends Plant Sci. 2008, 13, 329-334. [CrossRef] [PubMed]

3. Studniarek, C.; Egloff, S.; Murphy, S. Noncoding RNAs Set the Stage for RNA Polymerase II Transcription. Trends Genet. 2021, 37, 279-291. [CrossRef]

4. Hombach, S.; Kretz, M. Non-coding RNAs: Classification, Biology and Functioning. Adv. Exp. Med. Biol. 2016, 937, 3-17. [CrossRef] [PubMed]

5. Kapranov, P.; Cheng, J.; Dike, S.; Nix, D.A.; Duttagupta, R.; Willingham, A.T.; Stadler, P.F.; Hertel, J.; Hackermüller, J.; Hofacker, I.L.; et al. RNA Maps Reveal New RNA Classes and a Possible Function for Pervasive Transcription. Science 2007, 316, 1484-1488. [CrossRef]

6. Zhang, P.; Wu, W.; Chen, Q.; Chen, M. Non-Coding RNAs and their Integrated Networks. J. Integr. Bioinform. 2019, 16, 20190027. [CrossRef]

7. Kowalski, M.P.; Krude, T. Functional roles of non-coding Y RNAs. Int. J. Biochem. Cell Biol. 2015, 66, 20-29. [CrossRef]

8. Ponjavic, J.; Ponting, C.P.; Lunter, G. Functionality or transcriptional noise? Evidence for selection within long noncoding RNAs. Genome Res. 2007, 17, 556-565. [CrossRef]

9. Yang, X.; Liu, Y.; Zhang, H.; Wang, J.; Zinta, G.; Xie, S.; Zhu, W.; Nie, W.-F. Genome-Wide Identification of Circular RNAs in Response to Low-Temperature Stress in Tomato Leaves. Front. Genet. 2020, 11, 591806. [CrossRef] [PubMed]

10. Bhatia, G.; Sharma, S.; Upadhyay, S.K.; Singh, K. Long Non-coding RNAs Coordinate Developmental Transitions and Other Key Biological Processes in Grapevine. Sci. Rep. 2019, 9, 3552. [CrossRef] [PubMed] 
11. Deng, N.; Hou, C.; He, B.; Ma, F.; Song, Q.; Shi, S.; Liu, C.; Tian, Y. A full-length transcriptome and gene expression analysis reveal genes and molecular elements expressed during seed development in Gnetum luofuense. BMC Plant Biol. 2020, 20, 531. [CrossRef]

12. Jiang, N.; Cui, J.; Shi, Y.; Yang, G.; Zhou, X.; Hou, X.; Meng, J.; Luan, Y. Tomato lncRNA23468 functions as a competing endogenous RNA to modulate NBS-LRR genes by decoying miR482b in the tomato-Phytophthora infestans interaction. Hortic. Res. 2019, 6, 28. [CrossRef]

13. Yang, F.; Zhao, D.; Fan, H.; Zhu, X.; Wang, Y.; Liu, X.; Duan, Y.; Xuan, Y.; Chen, L. Functional Analysis of Long Non-Coding RNAs Reveal Their Novel Roles in Biocontrol of Bacteria-Induced Tomato Resistance to Meloidogyne incognita. Int. J. Mol. Sci. 2020, $21,911$. [CrossRef]

14. Gai, Y.P.; Yuan, S.S.; Zhao, Y.N.; Zhao, H.N.; Zhang, H.L.; Ji, X.L. A Novel LncRNA, MuLnc1, Associated with Environmental Stress in Mulberry (Morus multicaulis). Front. Plant Sci. 2018, 9, 669. [CrossRef] [PubMed]

15. Jiang, N.; Cui, J.; Hou, X.; Yang, G.; Xiao, Y.; Han, L.; Meng, J.; Luan, Y. Sl-lncRNA15492 interacts with Sl-miR482a and affects Solanum lycopersicum immunity against Phytophthora infestans. Plant J. 2020, 103, 1561-1574. [CrossRef]

16. Moh, N.M.M.; Zhang, P.; Chen, Y.; Chen, M. Computational Identification of miRNAs and Temperature-Responsive lncRNAs From Mango (Mangifera indica L.). Front. Genet. 2021, 12, 607248. [CrossRef] [PubMed]

17. Bai, Y.; Dai, X.; Li, Y.; Wang, L.; Li, W.; Liu, Y.; Cheng, Y.; Qin, Y. Identification and characterization of pineapple leaf lncRNAs in crassulacean acid metabolism (CAM) photosynthesis pathway. Sci. Rep. 2019, 9, 6658. [CrossRef] [PubMed]

18. Wong, D.C.J.; Matus, J.T. Constructing Integrated Networks for Identifying New Secondary Metabolic Pathway Regulators in Grapevine: Recent Applications and Future Opportunities. Front. Plant Sci. 2017, 8, 505. [CrossRef] [PubMed]

19. Yao, S.; Wang, Z.; Cao, Q.; Xie, J.; Wang, X.; Zhang, R.; Deng, L.; Ming, J.; Zeng, K. Molecular basis of postharvest granulation in orange fruit revealed by metabolite, transcriptome and methylome profiling. Postharvest Biol. Technol. 2020, 166, 111205. [CrossRef]

20. Zuo, J.; Grierson, D.; Courtney, L.T.; Wang, Y.; Gao, L.; Zhao, X.; Zhu, B.; Luo, Y.; Wang, Q.; Giovannoni, J.J. Relationships between genome methylation, levels of non-coding RNAs, mRNAs and metabolites in ripening tomato fruit. Plant J. 2020, 103, 980-994. [CrossRef]

21. Chen, Y.; Cheng, C.; Feng, X.; Lai, R.; Gao, M.; Chen, W.; Wu, R. Integrated analysis of lncRNA and mRNA transcriptomes reveals the potential regulatory role of lncRNA in kiwifruit ripening and softening. Sci. Rep. 2021, 11, 1671. [CrossRef]

22. Li, R.; Fu, D.; Zhu, B.; Luo, Y.; Zhu, H. CRISPR/Cas9-mediated mutagenesis of lncRNA1459 alters tomato fruit ripening. Plant J. 2018, 94, 513-524. [CrossRef] [PubMed]

23. Tang, Y.; Qu, Z.; Lei, J.; He, R.; Adelson, D.L.; Zhu, Y.; Yang, Z.; Wang, D. The long noncoding RNA FRILAIR regulates strawberry fruit ripening by functioning as a noncanonical target mimic. PLoS Genet. 2021, 17, e1009461. [CrossRef] [PubMed]

24. Liu, J.; Wang, H.; Chua, N.H. Long noncoding RNA transcriptome of plants. Plant Biotechnol. J. 2015, 13, 319-328. [CrossRef] [PubMed]

25. Cho, J.; Koo, D.H.; Nam, Y.W.; Han, C.T.; Lim, H.T.; Bang, J.W.; Hur, Y. Isolation and characterization of cDNA clones expressed under male sex expression conditions in a monoecious cucumber plant (Cucumis sativus L. cv. Winter Long). Euphytica 2006, 146, 271-281. [CrossRef]

26. Ma, J.; Yan, B.; Qu, Y.; Qin, F.; Yang, Y.; Hao, X.; Yu, J.; Zhao, Q.; Zhu, D.; Ao, G. Zm401, a short-open reading-frame mRNA or noncoding RNA, is essential for tapetum and microspore development and can regulate the floret formation in maize. J. Cell. Biochem. 2008, 105, 136-146. [CrossRef] [PubMed]

27. Liu, J.; Jung, C.; Xu, J.; Wang, H.; Deng, S.; Bernad, L.; Arenas-Huertero, C.; Chua, N.-H. Data from: Genome-wide analysis uncovers regulation of long intergenic noncoding RNAs in Arabidopsis. Plant Cell 2012, 24, 4333-4345. [CrossRef] [PubMed]

28. Wang, H.; Chung, P.J.; Liu, J.; Jang, I.C.; Kean, M.J.; Xu, J.; Chua, N.-H. Genome-wide identification of long noncoding natural antisense transcripts and their responses to light in Arabidopsis. Genome Res. 2014, 24, 444-453. [CrossRef]

29. Wang, H.; Niu, Q.W.; Wu, H.W.; Liu, J.; Ye, J.; Yu, N.; Chua, N.H. Analysis of non-coding transcriptome in rice and maize uncovers roles of conserved lncRNAs associated with agriculture traits. Plant J. 2015, 84, 404-416. [CrossRef]

30. Lv, Y.; Liang, Z.; Ge, M.; Qi, W.; Zhang, T.; Lin, F.; Peng, Z.; Zhaohua, P. Genome-wide identification and functional prediction of nitrogen-responsive intergenic and intronic long non-coding RNAs in maize (Zea mays L.). BMC Genom. 2016, 17, 350. [CrossRef]

31. Zhu, B.; Yang, Y.; Li, R.; Fu, D.; Wen, L.; Luo, Y.; Zhu, H. RNA sequencing and functional analysis implicate the regulatory role of long non-coding RNAs in tomato fruit ripening. J. Exp. Bot. 2015, 66, 4483-4495. [CrossRef]

32. Zhang, H.; Chen, X.; Wang, C.; Xu, Z.; Wang, Y.; Liu, X.; Kang, Z.; Ji, W. Long non-coding genes implicated in response to stripe rust pathogen stress in wheat (Triticum aestivum L.). Mol. Biol. Rep. 2013, 40, 6245-6253. [CrossRef]

33. Golicz, A.A.; Singh, M.B.; Bhalla, P.L. The Long Intergenic Noncoding RNA (LincRNA) Landscape of the Soybean Genome. Plant Physiol. 2018, 176, 2133-2147. [CrossRef]

34. Hou, X.; Du, Y.; Liu, X.; Zhang, H.; Liu, Y.; Yan, N.; Zhang, Z. Genome-Wide Analysis of Long Non-Coding RNAs in Potato and Their Potential Role in Tuber Sprouting Process. Int. J. Mol. Sci. 2017, 19, 101. [CrossRef] [PubMed]

35. Wang, T.-Z.; Liu, M.; Zhao, M.-G.; Chen, R.; Zhang, W.-H. Identification and characterization of long non-coding RNAs involved in osmotic and salt stress in Medicago truncatula using genome-wide high-throughput sequencing. BMC Plant Biol. 2015, 15, 131. [CrossRef] [PubMed]

36. Hao, Z.; Fan, C.; Cheng, T.; Su, Y.; Wei, Q.; Li, G. Genome-Wide Identification, Characterization and Evolutionary Analysis of Long Intergenic Noncoding RNAs in Cucumber. PLoS ONE 2015, 10, e0121800. [CrossRef] 
37. Zhang, Y.C.; Liao, J.Y.; Li, Z.Y.; Yu, Y.; Zhang, J.P.; Li, Q.F.; Qu, L.H.; Shu, W.S.; Chen, Y.Q. Genome-wide screening and functional analysis identify a large number of long noncoding RNAs involved in the sexual reproduction of rice. Genome Biol. 2014, 15, 512. [CrossRef] [PubMed]

38. Sharma, S.; Taneja, M.; Tyagi, S.; Singh, K.; Upadhyay, S.K. Survey of High Throughput RNA-Seq Data Reveals Potential Roles for lncRNAs during Development and Stress Response in Bread Wheat. Front. Plant Sci. 2017, 8, 1019.

39. Qi, X.; Xie, S.; Liu, Y.; Yi, F.; Yu, J. Genome-wide annotation of genes and noncoding RNAs of foxtail millet in response to simulated drought stress by deep sequencing. Plant Mol. Biol. 2013, 83, 459-473. [CrossRef]

40. Ding, J.; Lu, Q.; Ouyang, Y.; Mao, H.; Zhang, P.; Yao, J.; Xu, C.; Li, X.; Xiao, J.; Zhang, Q. A long noncoding RNA regulates photoperiod-sensitive male sterility, an essential component of hybrid rice. Proc. Natl. Acad. Sci. USA 2012, 109, $2654-2659$. [CrossRef]

41. Heo, J.B.; Sung, S. Vernalization-Mediated Epigenetic Silencing by a Long Intronic Noncoding RNA. Science 2011, 331, 76-79. [CrossRef] [PubMed]

42. Sun, Q.; Csorba, T.; Skourti-Stathaki, K.; Proudfoot, N.J.; Dean, C. R-Loop Stabilization Represses Antisense Transcription at the Arabidopsis FLC Locus. Science 2013, 340, 619-621. [CrossRef] [PubMed]

43. Csorba, T.; Questa, J.I.; Sun, Q.; Dean, C. Antisense COOLAIR mediates the coordinated switching of chromatin states at FLC during vernalization. Proc. Natl. Acad. Sci. USA 2014, 111, 16160-16165. [CrossRef]

44. Xu, X.-W.; Zhou, X.; Wang, R.-R.; Peng, W.-L.; An, Y.; Chen, L.-L. Functional analysis of long intergenic non-coding RNAs in phosphate-starved rice using competing endogenous RNA network. Sci. Rep. 2016, 6, 20715. [CrossRef] [PubMed]

45. Yuan, J.; Zhang, Y.; Dong, J.; Sun, Y.; Lim, B.L.; Liu, D.; Lu, Z.J. Systematic characterization of novel lncRNAs responding to phosphate starvation in Arabidopsis thaliana. BMC Genom. 2016, 17, 655. [CrossRef] [PubMed]

46. Tomato Genome Consortium. The tomato genome sequence provides insights into fleshy fruit evolution. Nature 2012, 485 , 635-641. [CrossRef]

47. Nie, W.F. DNA methylation: From model plants to vegetable crops. Biochem. Soc. Trans. 2021, 49, 1479-1487. [CrossRef] [PubMed]

48. Tang, D.; Gallusci, P.; Lang, Z. Fruit development and epigenetic modifications. New Phytol. 2020, 228, 839-844. [CrossRef] [PubMed]

49. Wang, J.; Yang, Y.; Jin, L.; Ling, X.; Liu, T.; Chen, T.; Ji, Y.; Yu, W.; Zhang, B. Re-analysis of long non-coding RNAs and prediction of circRNAs reveal their novel roles in susceptible tomato following TYLCV infection. BMC Plant Biol. 2018, 18, 104. [CrossRef] [PubMed]

50. Yang, Y.; Liu, T.; Shen, D.; Wang, J.; Ling, X.; Hu, Z.; Chen, T.; Hu, J.; Huang, J.; Yu, W.; et al. Tomato yellow leaf curl virus intergenic siRNAs target a host long noncoding RNA to modulate disease symptoms. PLOS Pathog. 2019, 15, e1007534. [CrossRef]

51. Yang, Z.; Yang, C.; Wang, Z.; Yang, Z.; Chen, D.; Wu, Y. LncRNA expression profile and ceRNA analysis in tomato during flowering. PLoS ONE 2019, 14, e0210650. [CrossRef]

52. Wang, X.; Ai, G.; Zhang, C.; Cui, L.; Wang, J.; Li, H.; Zhang, J.; Ye, Z. Expression and diversification analysis reveals transposable elements play important roles in the origin of Lycopersicon-specific lncRNAs in tomato. New Phytol. 2016, 209, 1442-1455. [CrossRef]

53. Zhao, T.; Mei, H.; Cao, Z.; Wang, L.; Tao, X.; Feng, S.; Fang, L.; Guan, X. Absence of CG methylation alters the long noncoding transcriptome landscape in multiple species. FEBS Lett. 2021, 595, 1734-1747. [CrossRef] [PubMed]

54. Wang, Y.; Gao, L.; Li, J.; Zhu, B.; Zhu, H.; Luo, Y.; Wang, Q.; Zuo, J. Analysis of long-non-coding RNAs associated with ethylene in tomato. Gene 2018, 674, 151-160. [CrossRef] [PubMed]

55. Yu, T.; Tzeng, D.T.W.; Li, R.; Chen, J.; Zhong, S.; Fu, D.; Zhu, B.; Luo, Y.; Zhu, H. Genome-wide identification of long non-coding RNA targets of the tomato MADS box transcription factor RIN and function analysis. Ann. Bot. 2018, 123, 469-482. [CrossRef] [PubMed]

56. Xiao, Y.; Kang, B.; Li, M.; Xiao, L.; Xiao, H.; Shen, H.; Yang, W. Transcription of lncRNA ACoS-AS1 is essential to trans-splicing between SIPsy1 and ACoS-AS1 that causes yellow fruit in tomato. RNA Biol. 2020, 17, 596-607. [CrossRef] [PubMed]

57. Xue, L.; Sun, M.; Wu, Z.; Yu, L.; Yu, Q.; Tang, Y.; Jiang, F. LncRNA regulates tomato fruit cracking by coordinating gene expression via a hormone-redox-cell wall network. BMC Plant Biol. 2020, 20, 162. [CrossRef]

58. Zhou, C.; Zhu, J.; Qian, N.; Guo, J.; Yan, C. Bacillus subtilis SL18r Induces Tomato Resistance Against Botrytis cinerea, Involving Activation of Long Non-coding RNA, MSTRG18363, to Decoy miR1918. Front. Plant Sci. 2021, 11, 634819. [CrossRef]

59. Cui, J.; Jiang, N.; Hou, X.; Wu, S.; Zhang, Q.; Meng, J.; Luan, Y. Genome-Wide Identification of lncRNAs and Analysis of ceRNA Networks During Tomato Resistance to Phytophthora infestans. Phytopathol. 2020, 110, 456-464. [CrossRef] [PubMed]

60. Cui, J.; Jiang, N.; Meng, J.; Yang, G.; Liu, W.; Zhou, X.; Ma, N.; Hou, X.; Luan, Y. LncRNA33732-respiratory burst oxidase module associated with WRKY1 in tomato- Phytophthora infestans interactions. Plant J. 2018, 97, 933-946. [CrossRef]

61. Cui, J.; Luan, Y.; Jiang, N.; Bao, H.; Meng, J. Comparative transcriptome analysis between resistant and susceptible tomato allows the identification of lncRNA16397 conferring resistance to Phytophthora infestans by co-expressing glutaredoxin. Plant J. 2017, 89, 577-589. [CrossRef] [PubMed]

62. Hou, X.; Cui, J.; Liu, W.; Jiang, N.; Zhou, X.; Qi, H.; Meng, J.; Luan, Y. LncRNA39026 Enhances Tomato Resistance to Phytophthora infestans by Decoying miR168a and Inducing PR Gene Expression. Phytopathology 2020, 110, 873-880. [CrossRef] [PubMed]

63. Liao, X.; Wang, J.; Zhu, S.; Xie, Q.; Wang, L.; Yu, H.; Ye, Z.; Yang, C. Transcriptomic and functional analyses uncover the regulatory role of lncRNA000170 in tomato multicellular trichome formation. Plant J. 2020, 104, 18-29. [CrossRef] 
64. Eom, S.H.; Lee, H.J.; Lee, J.H.; Wi, S.H.; Kim, S.K.; Hyun, T.K. Identification and Functional Prediction of Drought-Responsive Long Non-Coding RNA in Tomato. Agronomy 2019, 9, 629. [CrossRef]

65. Wang, Y.; Gao, L.; Zhu, B.; Zhu, H.; Luo, Y.; Wang, Q.; Zuo, J. Integrative analysis of long non-coding RNA acting as ceRNAs involved in chilling injury in tomato fruit. Gene 2018, 667, 25-33. [CrossRef]

66. Lin, Y.; Jiang, L.; Chen, Q.; Li, Y.; Zhang, Y.; Luo, Y.; Zhang, Y.; Sun, B.; Wang, X.; Tang, H. Comparative Transcriptome Profiling Analysis of Red- and White-Fleshed Strawberry (Fragaria $x$ ananassa) Provides New Insight into the Regulation of the Anthocyanin Pathway. Plant Cell Physiol. 2018, 59, 1844-1859. [CrossRef] [PubMed]

67. Feng, S.; Fang, H.; Liu, X.; Dong, Y.; Wang, Q.; Yang, K.Q. Genome-wide identification and characterization of long non-coding RNAs conferring resistance to Colletotrichum gloeosporioides in walnut (Juglans regia). BMC Genom. 2021, 22, 15. [CrossRef] [PubMed]

68. Yang, S.; Yang, T.; Tang, Y.; Aisimutuola, P.; Zhang, G.; Wang, B.; Li, N.; Wang, J.; Yu, Q. Transcriptomic profile analysis of non-coding RNAs involved in Capsicum chinense Jacq. fruit ripening. Sci. Hortic. 2020, 264, 109158. [CrossRef]

69. Ma, H.; Yang, T.; Li, Y.; Zhang, J.; Wu, T.; Song, T.; Yao, Y.; Tian, J. The long noncoding RNA MdLNC499 bridges MdWRKY1 and MdERF109 function to regulate early-stage light-induced anthocyanin accumulation in apple fruit. Plant Cell 2021, 33, 3309-3330. [CrossRef] [PubMed]

70. Yang, T.; Ma, H.; Zhang, J.; Wu, T.; Song, T.; Tian, J.; Yao, Y. Systematic identification of long noncoding RNA s expressed during light-Induced anthocyanin accumulation in apple fruit. Plant J. 2019, 100, 572-590. [CrossRef]

71. Li, Y.; Wu, C.; Liu, C.; Yu, J.; Duan, X.; Fan, W.; Wang, J.; Zhang, X.; Yan, G.; Li, T.; et al. Functional identification of lncRNAs in sweet cherry (Prunus avium) pollen tubes via transcriptome analysis using single-molecule long-read sequencing. Hortic. Res. 2019, 6, 135. [CrossRef] [PubMed]

72. Zhang, G.; Chen, D.; Zhang, T.; Duan, A.; Zhang, J.; He, C. Transcriptomic and functional analyses unveil the role of long non-coding RNAs in anthocyanin biosynthesis during sea buckthorn fruit ripening. DNA Res. 2018, 25, 465-476. [CrossRef]

73. Zhang, G.; Duan, A.; Zhang, J.; He, C. Genome-wide analysis of long non-coding RNAs at the mature stage of sea buckthorn (Hippophae rhamnoides Linn) fruit. Gene 2017, 596, 130-136. [CrossRef]

74. Liu, H.; Lu, Y.; Wang, J.; Hu, J.; Wuyun, T. Genome-wide screening of long non-coding RNAs involved in rubber biosynthesis in Eucommia ulmoides. J. Integr. Plant Biol. 2018, 60, 1070-1082. [CrossRef] [PubMed]

75. Li, W.; Li, C.; Li, S.; Peng, M. Long noncoding RNAs that respond to Fusarium oxysporum infection in 'Cavendish' banana (Musa acuminata). Sci. Rep. 2017, 7, 16939. [CrossRef]

76. Tian, Y.; Bai, S.; Dang, Z.; Hao, J.; Zhang, J.; Hasi, A. Genome-wide identification and characterization of long non-coding RNAs involved in fruit ripening and the climacteric in Cucumis melo. BMC Plant Biol. 2019, 19, 369. [CrossRef] [PubMed]

77. Parkhomchuk, D.; Borodina, T.; Amstislavskiy, V.; Banaru, M.; Hallen, L.; Krobitsch, S.; Lehrach, H.; Soldatov, A. Transcriptome analysis by strand-specific sequencing of complementary DNA. Nucleic Acids Res. 2009, 37, e123. [CrossRef] [PubMed]

78. Kim, D.; Langmead, B.; Salzberg, S.L. HISAT: A fast spliced aligner with low memory requirements. Nat. Methods 2015, 12, 357-360. [CrossRef] [PubMed]

79. Pertea, M.; Pertea, G.M.; Antonescu, C.M.; Chang, T.-C.; Mendell, J.T.; Salzberg, S.L. StringTie enables improved reconstruction of a transcriptome from RNA-seq reads. Nat. Biotechnol. 2015, 33, 290-295. [CrossRef] [PubMed]

80. Liao, Y.; Smyth, G.K.; Shi, W. featureCounts: An efficient general purpose program for assigning sequence reads to genomic features. Bioinformatics 2014, 30, 923-930. [CrossRef] [PubMed]

81. Garber, M.; Grabherr, M.G.; Guttman, M.; Trapnell, C. Computational methods for transcriptome annotation and quantification using RNA-seq. Nat. Methods 2011, 8, 469-477. [CrossRef] [PubMed]

82. Yang, X.; Zhang, X.; Yang, Y.; Zhang, H.; Zhu, W.; Nie, W.F. The histone variant Sl_H2A.Z regulates carotenoid biosynthesis and gene expression during tomato fruit ripening. Hortic. Res. 2021, 8, 85. [CrossRef] [PubMed]

83. Pauli, A.; Valen, E.; Lin, M.F.; Garber, M.; Vastenhouw, N.L.; Levin, J.; Fan, L.; Sandelin, A.; Rinn, J.; Regev, A.; et al. Systematic identification of long noncoding RNAs expressed during zebrafish embryogenesis. Genome Res. 2011, 22, 577-591. [CrossRef] [PubMed]

84. Shuai, P.; Liang, D.; Tang, S.; Zhang, Z.; Ye, C.-Y.; Su, Y.; Xia, X.; Yin, W. Genome-wide identification and functional prediction of novel and drought-responsive lincRNAs in Populus trichocarpa. J. Exp. Bot. 2014, 65, 4975-4983. [CrossRef] [PubMed] 